\title{
Macrocell Processes in Reinforced Concrete Structures
}

\author{
Josep R. Lliso-Ferrando, José E. Ramón Zamora, Román Bataller and Juan Soto
}

Instituto Interuniversitario de Investigación de Reconocimiento Molecular y Desarrollo Tecnológico (IDM), Universitat Politècnica de València, Camino de Vera, s/n 46022 Valencia, Spain. E-mail: jollife2@arq.upv.es

\begin{abstract}
Corrosion of steel embedded in reinforced concrete is the phenomena that most affects the durability of this type of structures. The control and analysis of the rebars can help detect this problem beforehand, contributing to prevent costly repairs made when the damage is quite advanced. Currently, there are several techniques for measuring the corrosion rate of steel, but they have the disadvantage of being slow or requiring specialized tools. In addition, these techniques need direct connection to the rebars, so removing the concrete cover layer is necessary. This destructive technique is sometimes impossible to do because there are analysis zones which are inaccessible due to they are buried or submerged. Recently, using sensors embedded previously casting and external electrical connections let analyse the corrosion without using invasive techniques. This study presents the complementary technique of analysing macrocell currents in order to know the origin and direction of current in reinforcements. This technique requires less time and non-advanced material, only an ammeter and electrical connection to the rebars, executed before casting. In addition, this parameter provides information about the real corrosion of the different parts of the structure. In this study it is performed the laboratory analysis of this technique by the use of specimens containing one anode and one cathode inside them creating a macrocell. The influence of different environments on macrocell current intensities shall be studied and compared with other studied parameters as corrosion density.
\end{abstract}

Keywords: Macrocell Currents, Reinforced Concrete Durability, Corrosion Potential, Corrosion Density, Concrete Resistivity.

\section{Introduction}

Reinforced concrete is the most used construction material worldwide due to its characteristics, mechanical properties, low-cost and durability. The durability concept is defined as the ability to withstand the mechanical actions, environmental conditions, chemical attack or any other kind of damage that affects the initial state and reduces the lifespan. Durability parameter became a key aspect during design process since nineties. (Tang et al., 2015; Garcés et al., 2008).

One of the most frequent problems that affects the durability of reinforced concrete structures is the corrosion of the rebars. High alkalinity generated by cement matrix ( $\mathrm{pH}$ usually higher than 12.5) generates a passive layer on the reinforcements, which is transparent, continuous, compact and protects the rebars. In addition, the cement matrix entails a dense barrier between the rebars and the atmosphere where pieces are located. Nevertheless, the cover layer is porous and presents a certain permeability to gas and water, becoming an access path for aggressive agents. The aggressive agents, as chlorides or $\mathrm{CO}_{2}$ are able to destroy the passive layer and trigger active corrosion, which is the main cause of reinforced concrete structures failure (Bertolini et al., 2013; Garcés et al.,2008).

One of the greatest problems of steel corrosion in reinforced concrete is its difficult 
detection. Corrosion phenomena develops itself internally and it is visible externally once the damage is quite advanced, through rust stains or cover layer cracks. As a result, corrosion generates expensive repairs due to the belated detection and the necessity of periodic reviews because it is not possible to eradicate the problem completely. Last reports and statistics show the great amount governments invest for repair of reinforced concrete structure (François et al., 2018).

During the last twenty years, a lot of corrosion measurement techniques have emerged in order to help detecting corrosion beforehand. The main disadvantage of these techniques is the rebar connection necessity, so removing the concrete cover layer is required. Sometimes, this fact is impossible when the structural elements are submerged or buried. (Andrade et al., 2001; Bertolini et al., 2013; Ramon Zamora, 2018; Ramón Zamora et al. 2016).

Using sensors embedded before casting has become an alternative during last years. Electrical connections executed previously casting let analyse the local corrosion without using invasive techniques. However, most of data collection require a lot of time or specific tools, which are really expensive (Ramón Zamora et al., 2016; Ramon Zamora, 2018).

The main inconvenient of using isolated sensors for corrosion monitoring is that it can be only measured the local corrosion. However, in structures, real corrosion is completely different to the local corrosion due to macrocell currents. Different parts of the reinforcements are electrically connected and macrocell currents generate currents becoming areas in anodes and cathodes.

This study shows

complementary meas the currents direction (cathodes). In addition, of the reinforcements

2 Macrocell Currents Analysis

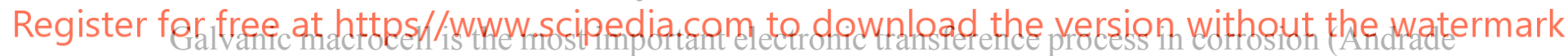

et al., 1992). The macrocell is generated by the presence of great passive areas connected electricalily to active areas, where corrosion phenomenon occurs. In this situation, active zones are the anodes (electrons source), while the rest of the passive rebars are the cathode, and the porous dissolution of the cement matrix serves as the electrolyte (Andrade et al., 2008; Bertolini et al., 2013).

Some authors highlight macrocell corrosion is produced together with microcell corrosion (Andrade et al., 1992; Ji et al., 2013). The last one is due to heterogeneity of the material, creating small microcells between the different phases of the microstructure. In Figure 1, it is possible to see the difference between microcells and macrocells.

The macrocell current is measured with a Zero Resistance Ammeter (ZRA) (Andrade et al., 2008). Using ZRA in laboratory is possible due to specimens where anode and cathode have not electrical contact can be manufactured. However, measurements in real structures are impossible due to there are electrical contacts between rebars. In this case, it should be necessary to isolate one part of the reinforcements, becoming this measurement an invasive technique. Including isolated sensors and using electrical connections executed before casting would avoid destructive techniques and would facilitate the measurements. 


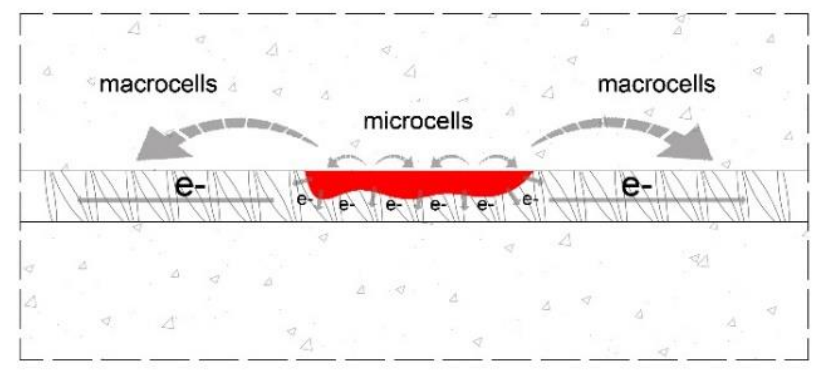

Figure 1. Macrocells and microcells.

\subsection{Previous Work}

Previously to this study, a macrocell analysis was performed using small specimens and different dosages (Lliso-Ferrando et al., 2019). During the first phase of this analysis, cylindrical test specimens where measured as it is shown in Figure 2. The corrosion process is slower than using impressed current, but it allows to observe the corrosion phenomena in a more natural way. The rebar works as anode and the stainless steel plates are the cathodes, which demand electrons to the carbon steel due to the oxygen availability in water.
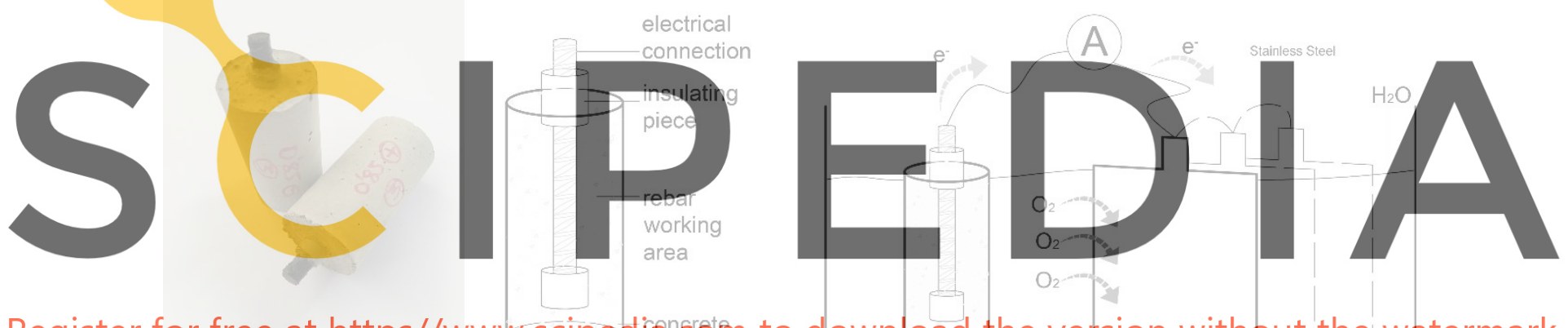

Register for free at https//www.scipedian.erom to download the version without the watermark

Figure 2. Test specimen and testing procedure.

The study allowed to analyse the influence between cathode-anode surface ratio in the corrosion intensities, as it is possible to see in Figure 3. Several specimens with different mixes were studied. The anode surface is always the same (specimen), and the cathode surface increase gradually (stainless steel plates). As shown in Figure 3, once the ratio between anode and cathode surface exceed $1 / 350$, the macrocell intensity stabilizes because the anode is not able to provide more electrons. As it is possible to appreciate, depending on the concrete characteristics, the ratio can be lower if the concrete quality is better (lower water/cement ratio).

During the second phase of this study, the specimens were exposed in 24 hours' periods to different environments (Laboratory conditions $\left(65 \%\right.$ R.H. and $20^{\circ} \mathrm{C}$ ), Saturated, $100 \%$ R.H., dry $\left(40^{\circ} \mathrm{C}\right.$ and $23 \%$ R.H.)). In every atmosphere, macrocell intensities were measured. It was found the cyclic tendency of this parameter. However, the cathode (stainless steel mesh) was joined to the specimen using a wet cloth. This situation simulated a hypothetic case. 


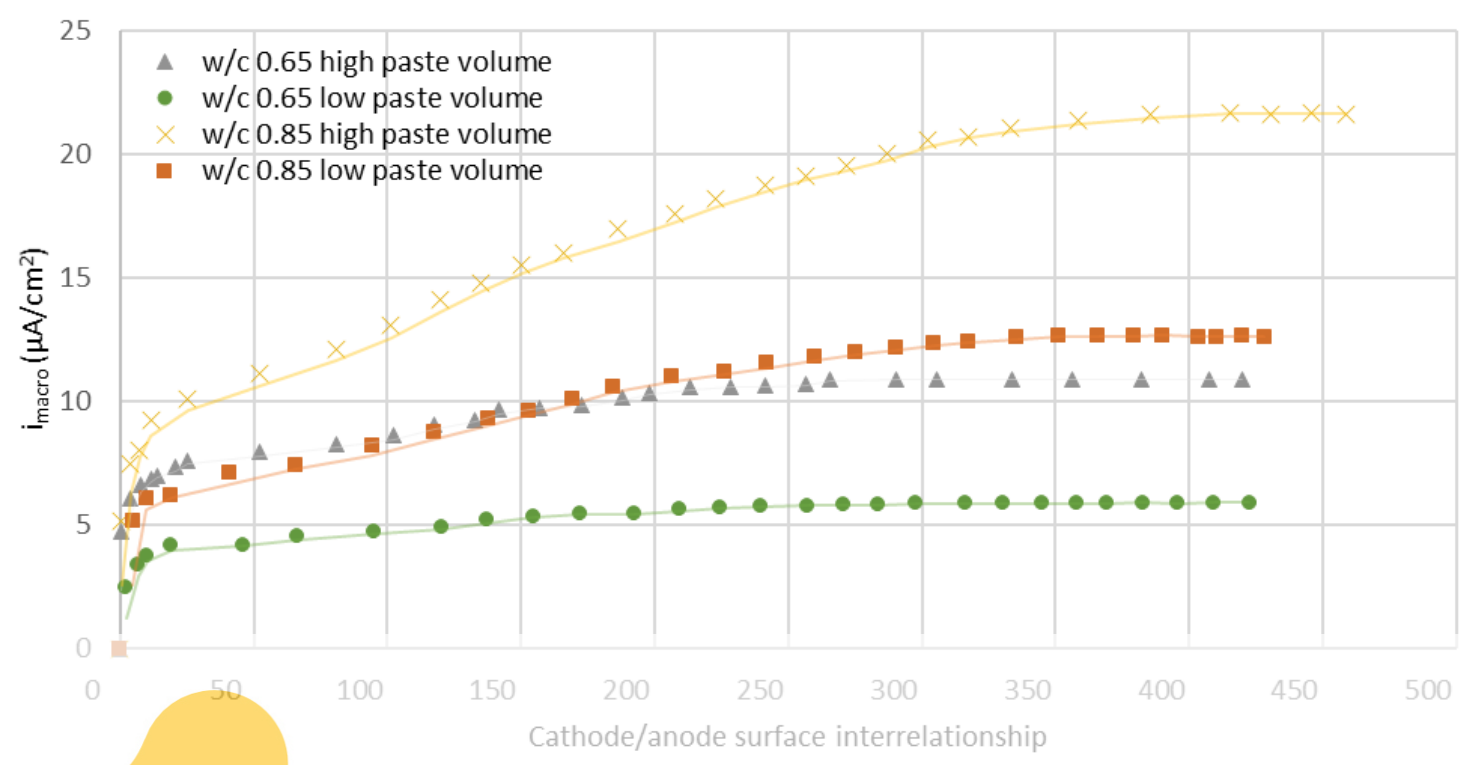

Figure 3. Cathode/anode surface ratio for several specimens with different W/C ratio.

In the present case study, the analysis is carried out on specimens where anode and cathode

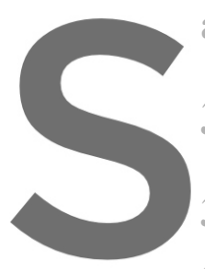
are embedded in concret

\section{Experimental}

3.1 Materials
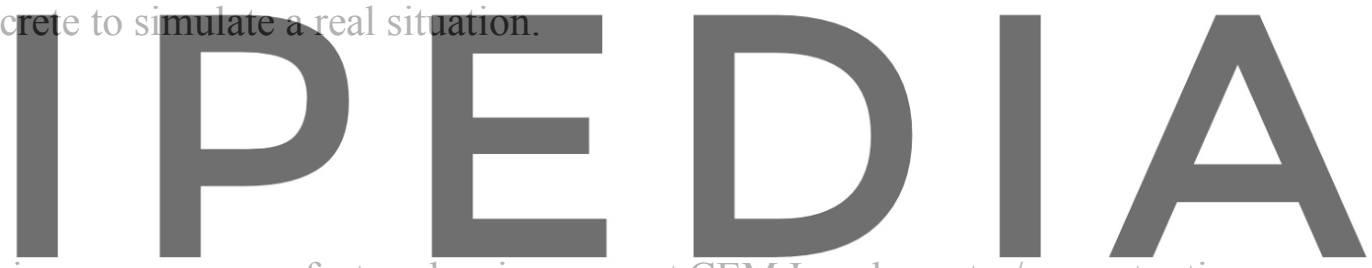

Several concrete specimens were manufactured, using cement CEM I, and a water/cement ratio

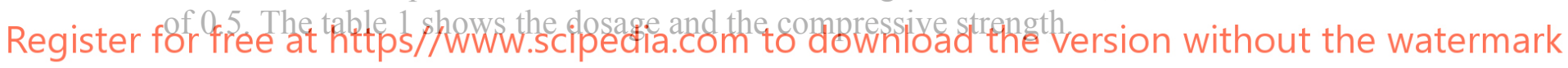

Table 1. Dosage of concrete per weight.

\begin{tabular}{cccccc}
\hline $\mathrm{f}_{\mathrm{c}}$ & $\mathrm{w} / \mathrm{c}$ & Cement* $^{*}$ & Water & Superplasticizer & Sand \\
\hline $47.3 \mathrm{Mpa}$ & 0.5 & 360 & 180 & 1.1 & 1872 \\
\hline & & ${ }^{*}$ CEM I 42.5. & &
\end{tabular}

\subsection{Test Specimens}

In Figure 4, test specimens' schemes and pictures are shown. The measurements were carried out on cylindrical specimens with a diameter of $100 \mathrm{~mm}$ and a height of $200 \mathrm{~mm}$. Inside the specimen, a rebar was embedded $(\varnothing 1.2 \times 16 \mathrm{~cm})$ having electrical connection. A stainless steel mesh was embedded having a cable for electrical connection too. Using different steels, noblest metal is the cathode (stainless steel), while rebar is the anode (carbon steel), it is possible to create a macrocell when they are connected. 


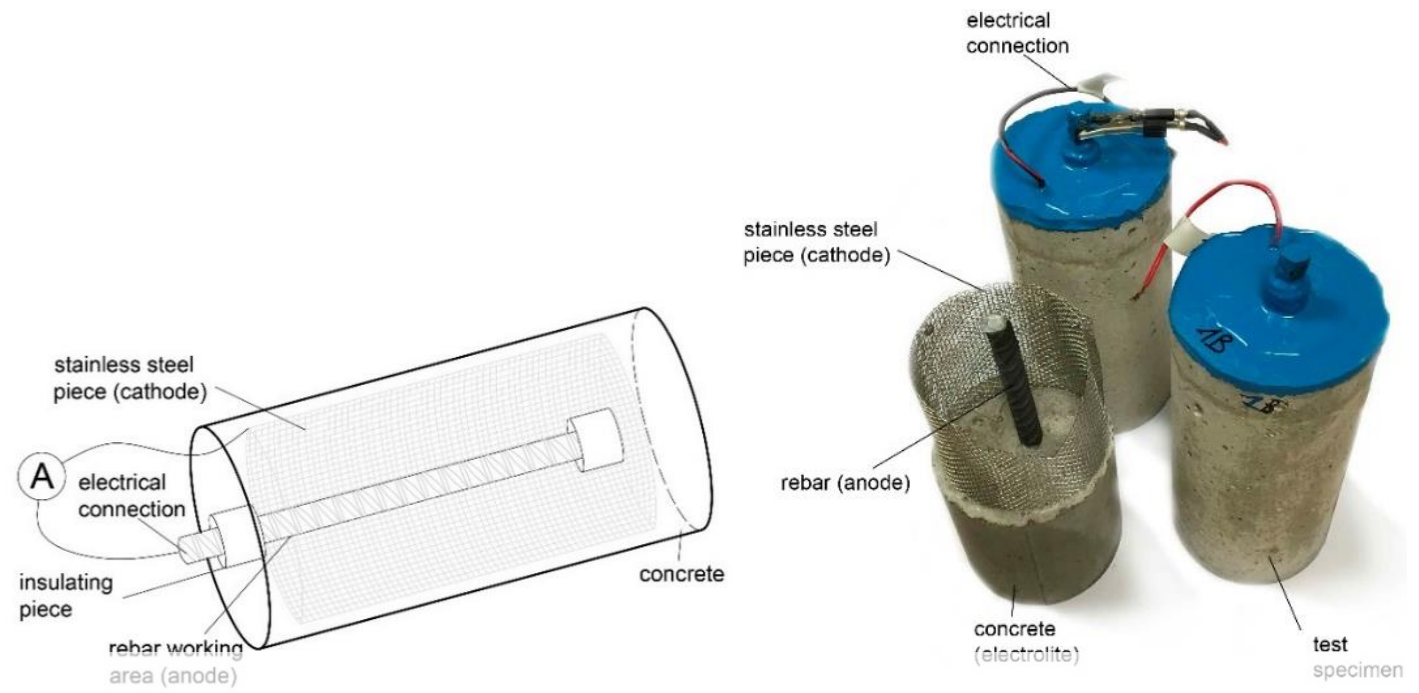

Figure 4. Test specimens.

\subsection{Measurements}

After 28 days of casting and curing, specimens were exposed to accelerated carbonation process. The chamber conditions were $20^{\circ} \mathrm{C}, 65 \%$ R.H. and $30 \% \mathrm{CO}_{2}$. The specimens were located in the chamber until they were completely carbonated. This period lasted two months.

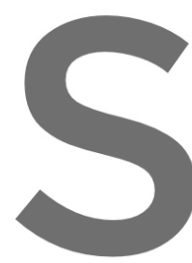
This process allowed to

Once rebars were dep 24 hours' periods. At th

corrosion currents were connected and just for measuring they were di
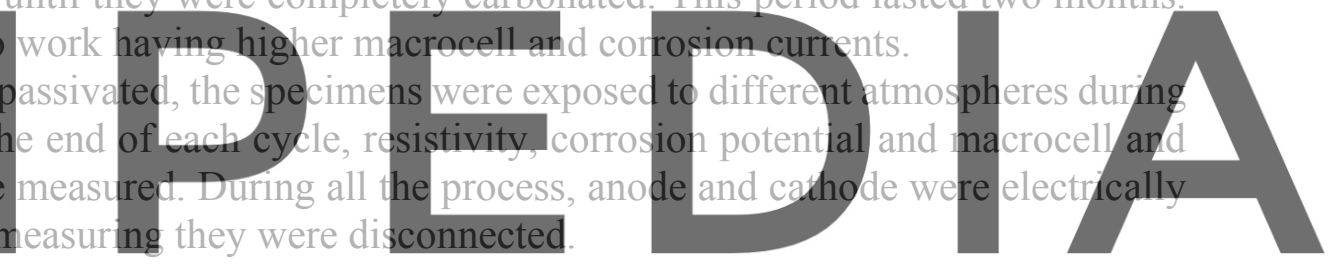

The specimens were exposed to four different atmospheres: dry atmosphere $\left(40^{\circ} \mathrm{C}\right.$ and $23 \%$

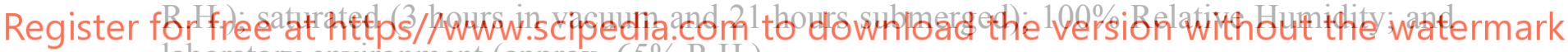
laboratory environment (approx. 65\% R.H.).

Macrocell measurements were carried out with a ZRA.

\section{Results}

Figure 5 shows the macrocell and local corrosion currents evolution during the different cycles when concrete samples were exposed to different environments after carbonation process. As shown in Figure 5, macrocell currents have a cyclic tendency related to the changes in the environment where test specimens are located.

In addition, it is possible to appreciate how local corrosion intensity values also change depending on the atmosphere where specimens are located. This is due to the fact there are different humidity levels in each environment. On the one hand, when specimens are in a $40^{\circ} \mathrm{C}$ and $23 \%$ R.H. atmospheres, there is barely enough humidity for let ionic transfer between anode and cathode, and intensities show lower values. Otherwise, when specimens are located in humid environments, presence of water allows the ionic transfer and intensity values doubled their previous ones. 


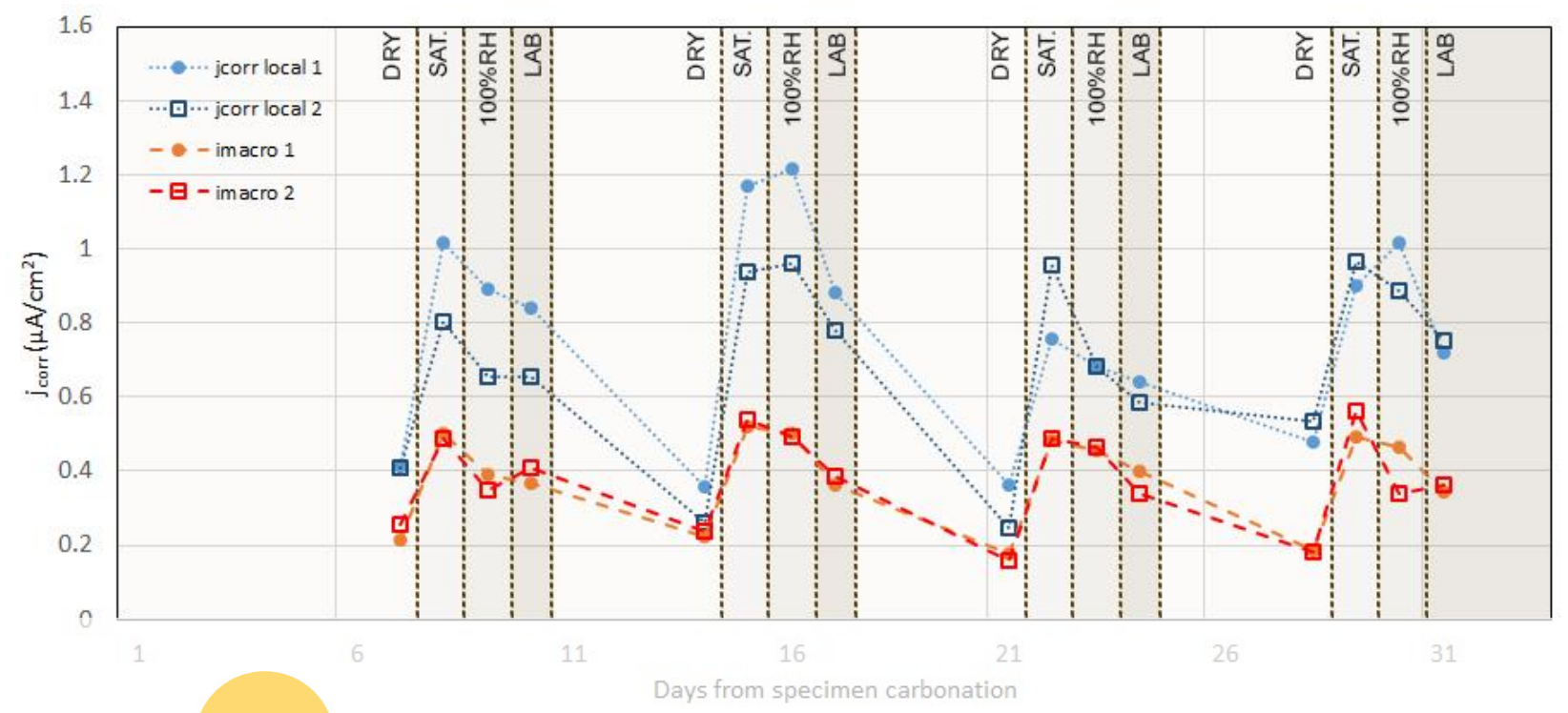

Figure 5. Macrocell current and local corrosion current cyclic variations.

Furthermore, we can appreciate there are not variations between macrocell intensities in specimens 1 and 2, despite having different cathode surfaces. As it was commented on Figure 3 , depending on the

generate no differences

1 was $1 / 10$ and in specimen 2 was $1 / 20$.

good quality (lower water

Figure 6 shows the a it is possible to appreciate the total corrosion in
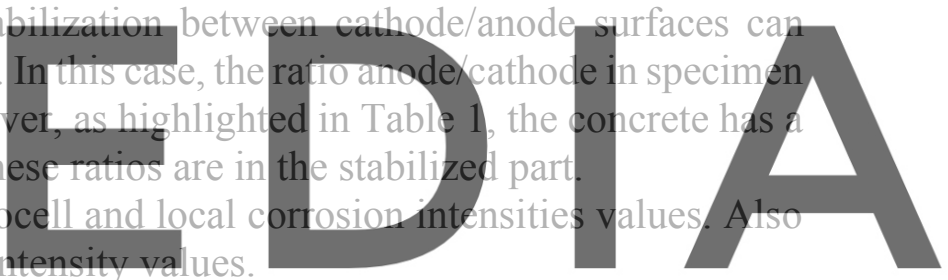

Register for free at https//www.scipedia.com to download the version without the watermark

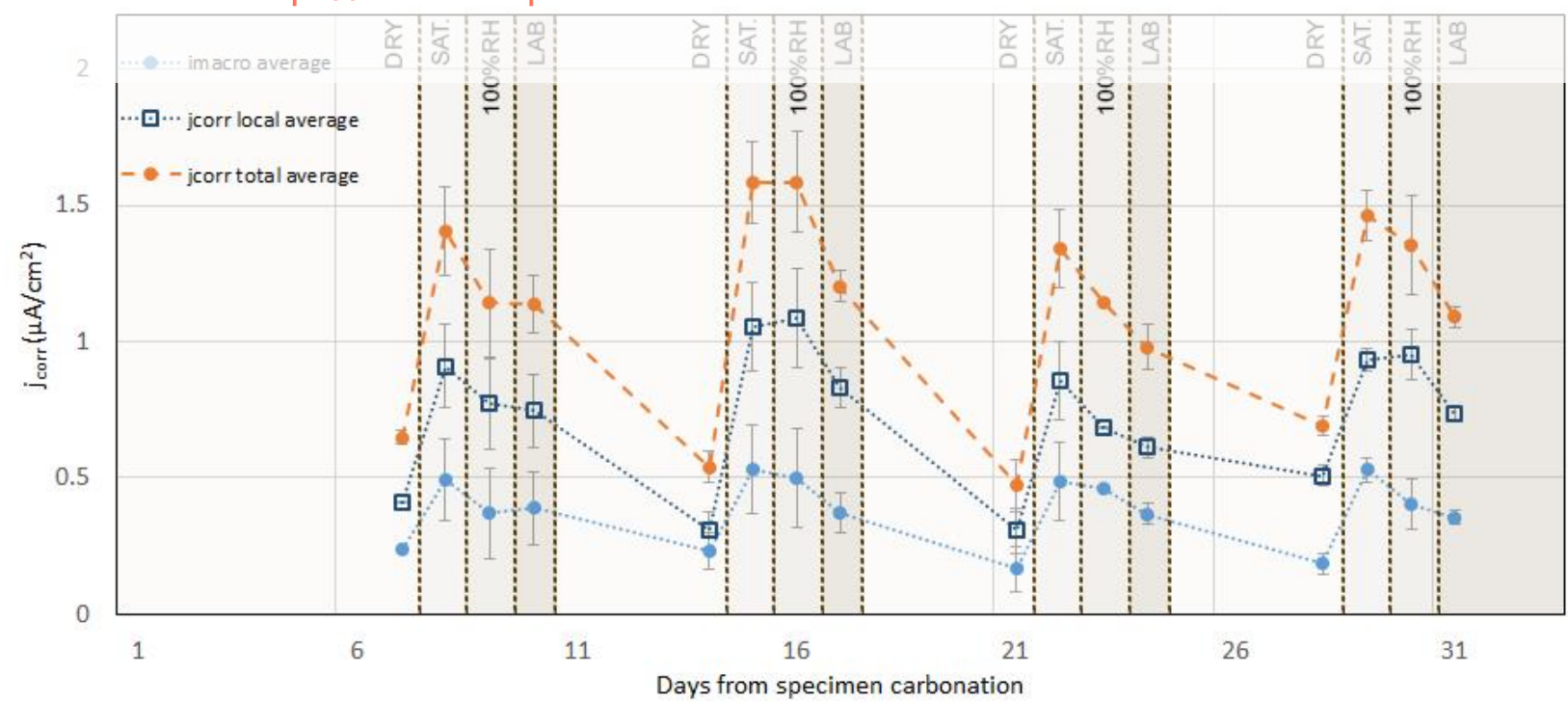

Figure 6. Macrocell and local corrosion intensities and the total corrosion intensity. 
Total corrosion intensity has been obtained from the sum of macrocell intensity and local corrosion intensity. As shown in Figure 6, macrocell intensities ranged between 30\%-40\% from the total corrosion intensities. This fact highlights we mustn't underestimate the macrocell created in the reinforcements.

\section{Conclusions}

In this study, it has been shown the importance of analysing the macrocell currents in order to understand and know the real corrosion currents in rebars embedded in reinforced concrete structures. The experimental analysis has let to check the behaviour of macrocell and local corrosion intensities in different atmospheres. It has been possible to appreciate the relation of these parameters and the humidity/water presence in the cement matrix.

This study shows using sensors for analysing the local corrosion can lead to wrong results. Overlooking the macrocell currents it is possible to obtain corrosion values 30\%-40\% lower than the real corrosion intensities.

The main purpose of this study was understanding the macrocell currents in order to become possible the macrocell currents real-time monitoring in reinforced concrete structures. This fact can become an important tool in order to complement the corrosion analysis of the steel embedded in reinforced concrete structures.
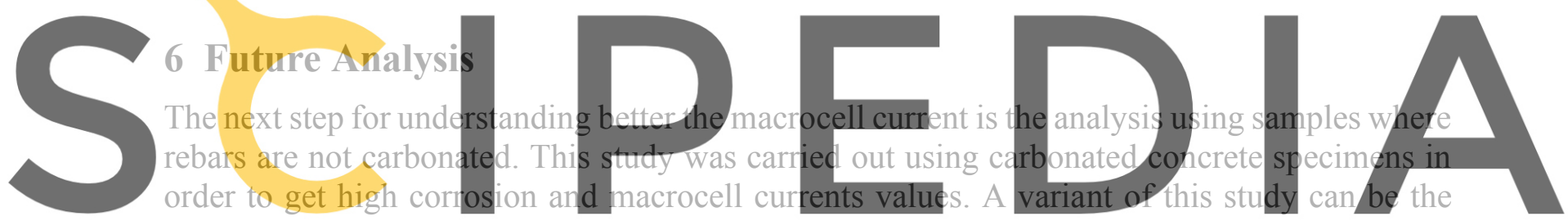
analysis of corrosion and macrocell currents before the rebars depassivation and afterwards.

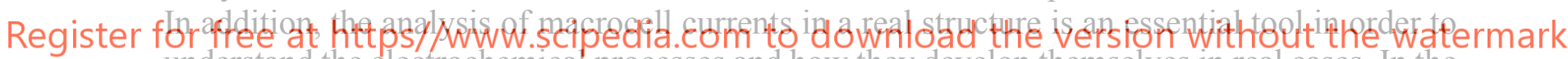
understand the electrochemical processes and how they develop themselves in real cases. In the electrochemical laboratory of ETSIE, in UPV, a 20 meters long beam was manufactured two years ago. The beam is located in the campus gardens and it was exposed to the weather conditions. The piece includes several reinforcements embedded in order to observe the macrocell currents. The rebars are still passive and in a short-them period, the macrocell and corrosion intensities will be monitored and analysed in passive state and once they are depassivated.

\section{Acknowledgements}

The authors would like to express their gratitude to the Universitat Politècnica de València for the pre-doctoral scholarship granted to Josep Ramon Lliso Ferrando (FPI-UPV-2018). To the Spanish Ministry of Economy and Competitiveness for the financial support from the national program of oriented research, development and Innovation to societal challenges (ref. BIA2016-78460-C3-3-R). 


\section{ORCID}

Josep Ramon Lliso Ferrando: https://orcid.org/0000-0002-2457-9024

José Enrique Ramón Zamora: https://orcid.org/0000-0002-6765-1735

Román Bataller Prats: https://orcid.org/0000-0003-2429-806X

Juan Soto Camino: https://orcid.org/0000-0001-5055-2768

\section{References}

Andrade, C., Garcés, P. and Martínez, I. (2008). Galvanic Currents and Corrosion Rates of Reinforcements Measured in Cells Simulating Different Pitting Areas Caused by Chloride Attack in Sodium Hydroxide. Corrosion Science 50 (10): 2959-64. https://doi.org/10.1016/j.corsci.2008.07.013.

Andrade, C., Maribona, I., Feliu, S. and González, J. A. (1992). The Effect of Macrocells between Active and Passive Areas of Steel Reinforcements. Corrosion Science 33: 237-49.

Andrade, C., Martínez, I., Alonso, C. and Fullea, J. (2001). New Advanced Electrochemical Techniques for on Site Measurements of Reinforcement Corrosion. Materiales de Construccion 2001 (263-264): 97-107. https://doi.org/10.3989/mc.2001.v51.i263-264.356.

Bertolini, L., Elsener, B., Pedeferri, P., Redaelli, E. and Polder, R. (2013). Corrosion of Stell in Concrete: Prevention, Diagnosis and Repair. Edited by Wiley VCH.

Raoul, F., Laurens, S. and Deby, F. (2018). Corrosion and Its Consequences for Reinforced Concrete Structures. ISTE Press Ltd and Elsevier Ltd. https://doi.org/10.1016/c2016-0-01228-7.

Garcés, P., Climent, M. A. and Zornoza, E. (2008). Corrosión de Armaduras En Estructuras de Hormigón Armado (in Spanish). Editorial Club Universitario.

Yong, J., Zhao, W., Zhou, M., Hui, M. and Zeng, P. (2013). Corrosion Current Distribution of Macrocell and Microcell of Steel Bar in Concrete Exposed to Chloride Environments. Construction and Building Materials 47: 104-10. https://doi.org/10.1016/j.conbuildmat.2013,05,003.

Lliso-Ferrando, J. R., Ramón, J. E Characterization in Reinforced C

Ramón, J. E., Gandía-Romero, J. I Monitoring Steel Corrosion in Technology and Sustainability 1 (1): 65. https://doi
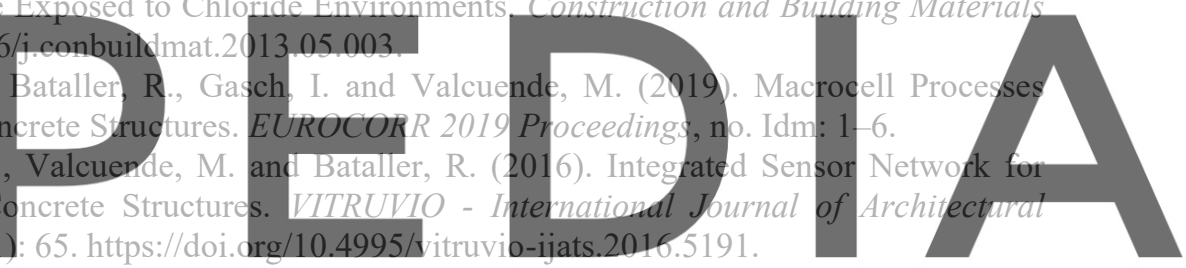

Ramon, J. E. (2018). Sistema de Sensores Embebidos Para Monitorizar La Corrosión En Estructuras de Hormigón

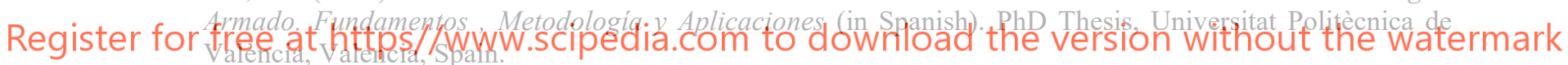

Tang, S. W., Yao, Y, Andrade, C. and Li, Z. (2015). Recent Durability Studies on Concrete Structure. Cement and Concrete Research 78: 143-54. https://doi.org/10.1016/j.cemconres.2015.05.021. 